\title{
Physiological and pathological consequences of cellular senescence
}

\author{
Dominick G. A. Burton • Valery Krizhanovsky
}

Received: 29 May 2014/Revised: 21 July 2014/ Accepted: 23 July 2014 / Published online: 31 July 2014

(C) The Author(s) 2014. This article is published with open access at Springerlink.com

\begin{abstract}
Cellular senescence, a permanent state of cell cycle arrest accompanied by a complex phenotype, is an essential mechanism that limits tumorigenesis and tissue damage. In physiological conditions, senescent cells can be removed by the immune system, facilitating tumor suppression and wound healing. However, as we age, senescent cells accumulate in tissues, either because an aging immune system fails to remove them, the rate of senescent cell formation is elevated, or both. If senescent cells persist in tissues, they have the potential to paradoxically promote pathological conditions. Cellular senescence is associated with an enhanced pro-survival phenotype, which most likely promotes persistence of senescent cells in vivo. This phenotype may have evolved to favor facilitation of a short-term wound healing, followed by the elimination of senescent cells by the immune system. In this review, we provide a perspective on the triggers, mechanisms and physiological as well as pathological consequences of senescent cells.
\end{abstract}

Keywords Aging - Age-related disease .

Immune surveillance $\cdot$ DNA damage response

\section{Overview}

In response to cellular stress, often resulting in DNA damage, proliferating cells can initiate a program that leads to a permanent cell cycle arrest termed cellular senescence. The short-term induction of cell senescence

D. G. A. Burton · V. Krizhanovsky $(\bowtie)$

Department of Molecular Cell Biology, The Weizmann Institute of Science, 76100 Rehovot, Israel

e-mail: valery.krizhanovsky@weizmann.ac.il has beneficial roles in tumor suppression, wound healing and possibly embryonic development (Fig. 1). However, the long-term presence of senescent cells in tissues has the potential to promote age-related disease and cancer in a cell in non-autonomous manner. In this review, we discuss the various triggers and mechanisms of cell senescence, the physiological and pathological consequences of the senescence program, the ability of senescent cells to interact with immune cells and provide possible explanations for why senescent cells may persist in tissues.

\section{Triggers and molecular pathways of cell senescence}

Cell senescence can be induced by various stimuli, all of which engage similar molecular pathways to initiate and sustain the senescence program (Fig. 1). The first experimental evidence for the existence of such a program was provided by Hayflick and Moorehead [1] more than 50 years ago. They demonstrated that cultured cells have a maximum limit on the number of cellular divisions that can be undertaken. This replicative limit is a result of the gradual shortening of telomeres due to an inability of replicative polymerases to synthesize DNA at chromosome ends [2, 3]. Chromosome ends consist of a telomere end complex made up of telomeric proteins that protects chromosome ends from being recognized as a double strand break, thereby preventing a DNA damage response (DDR). However, when a telomere becomes critically short, it can no longer be protected and induces a DDR that triggers cell senescence, referred to as replicative senescence (RS) [4]. Telomere elongation by telomerase, an enzyme that adds telomeric repeats back to chromosome ends, protects cells from RS [5, 6]. 


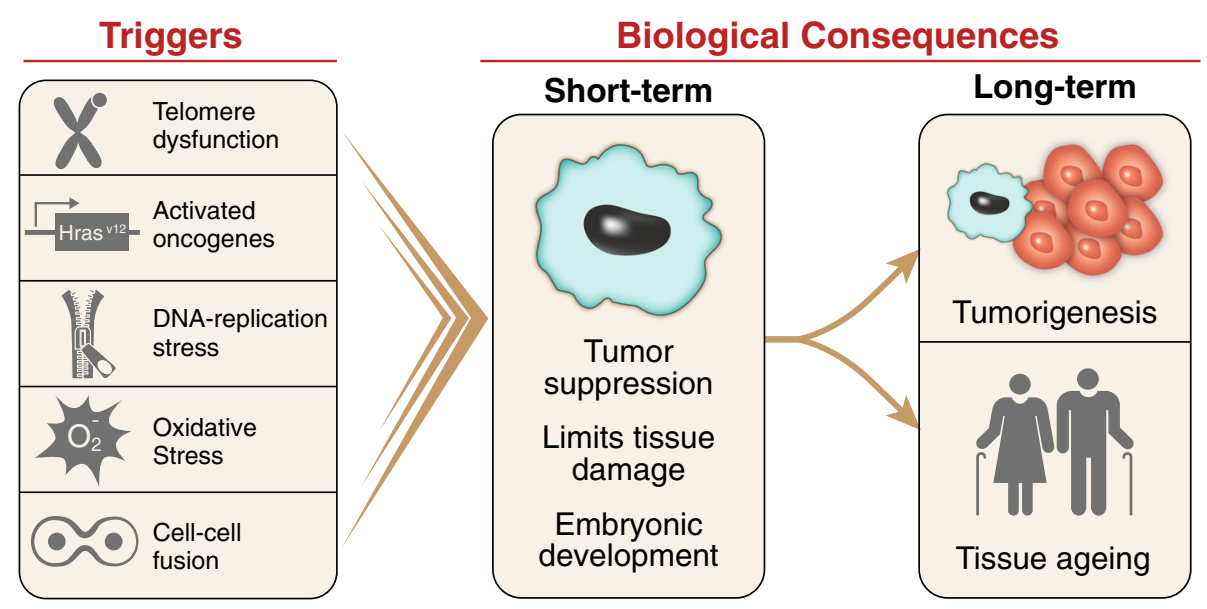

Fig. 1 Biological consequences of cellular senescence. Cellular senescence can be induced by various triggers, including, but not limited to, telomere dysfunction, oncogene activation, reactive oxygen species and cell-cell fusion. Short-term presence of senescent cells plays a beneficial role in tumor suppression, wound healing and embryonic development. However, the long-term persistence of senescent cells in tissues can paradoxically promote tumorigenesis and development of age-related diseases
In addition to RS, cell senescence can be initiated by other stimuli that prematurely induce cell senescence independent of telomere length. The activation of oncogenes such as $R A S$ [7] and $R A F$ [8] also induces cell senescence, referred to as oncogene-induced senescence (OIS). This form of cell senescence is associated with tumor suppression. A recent genomic study on the comparison of RS cells and OIS cells show that while there are some common gene expression changes between RS and OIS compared to proliferating cells, there are also substantial differences [9]. Although initially limited to in vitro studies, numerous findings suggest that OIS might be mediated, at least partially, by the induction of DNA damage, often associated with elevated reactive oxygen species (ROS) levels [10-14]. Activation of ERK has also been shown to be required for Ras-induced senescence by promoting the degradation of proteins required for cell cycle progression [15]. It also appears that cell replication is required to activate a DDR via oncogene activation, since oncogene expression does not trigger a DDR in the absence of DNA replication [11]. However, the contribution of DDR to OIS in vivo is not completely understood and requires further characterization. Moreover, mutant oncogenes, for example $H$-ras ${ }^{G 12 V}$, have the potential to activate molecular pathways of cell senescence such as p38 and NF-kB independent of DNA damage. In addition, oncogenic Ras can promote the up-regulation of p53 via p19ARF independent of DNA damage in mice [16]. Therefore, the induction of cell senescence in the absence of DNA damage cannot be excluded [17].

DNA damage induced by ionizing radiation, UV light, chemotherapeutic drugs and pathological increases in intracellular and extracellular ROS can also activate the senescence program. This type of cell senescence is often referred to as stress-induced premature senescence (SIPS) [18], because it occurs independent of telomere length, similar to OIS. The induction of SIPS is completely dependent upon a DDR. As with OIS, phenotypically SIPS and RS appear to be similar in many ways, but it has been shown that they can differ at the level of protein expression [19]. Age-related impairment in mitochondrial and antioxidant enzyme systems may lead to an increase in ROSrelated damage [20]. Various forms of ROS such as hydrogen peroxide, superoxide and hydroxyl radicals can inflict DNA damage, particularly at telomeres potentially leading to induction of SIPS $[18,21]$. Whether SIPS plays a role in normal physiological aging is still debatable, as increased expression of several antioxidant enzymes did not extend the lifespan in mice [22].

In many cases, the above-mentioned triggers of cell senescence lead to the activation of a DDR. It is known that while mild DNA damage can induce a transient growth arrest and extensive DNA damage can induce programmed cell death, persistent DNA damage induces cell senescence [23]. The molecular determinants that regulate the switch from transient growth arrest to irreversible growth arrest are becoming more complex and have yet to be fully determined. However, in general terms, the induction of DNA damage initially activates the p53-p21 pathway to facilitate cell cycle arrest [24]. This pathway is the main driving force for induction of the senescence program. When DNA damage cannot be resolved, p16(INK4a) appears to regulate the long-term maintenance of permanent cell cycle arrest by induction of chromatin changes through $\mathrm{Rb}$ pathway $[7,25,26]$. However, cell senescence can also occur independent of p53 and p21 in the presence 
of DNA damage, which appears to be dependent upon p16(INK4a) [27, 28]. The factors determining why cells enter senescence through the p53/p21 pathways or via p16(INK4a) independent of p53/p21 are not fully understood. It can be suggested that they may be related to the type of initiating stimulus, the extent of DNA damage, cell type-specific differences in the initial levels of p16(INK4a) or the ability to induce its expression. The presence of DNA damage and subsequent up-regulation of p16(INK4a) in quiescent cells in vivo may also induce a pre-senescent state that converts to a full senescent state when cells are stimulated to proliferate [29]. This suggests that DNA replication is required to induce a persistent DDR associated with cell senescence. In vitro, a conversion from transient cell cycle arrest induced by experimental overexpression of p21 to permanent cell cycle arrest has also been described and appears to be dependent upon continuous mTOR activation in response to growth factors [30]. While the induction of cellular senescence via DNA damage is irreversible, induction of long-term cell cycle arrest via p21 overexpression may be reversible if mTOR is inhibited [30].

The induction of persistent DNA damage signaling is not only necessary for induction of permanent cell cycle arrest, but it also facilitates the secretion of soluble factors, including pro-inflammatory cytokines, growth factors and proteases [23]. The secretion of these soluble factors in senescent cells appears to be regulated through p38 and $\mathrm{NF \kappa B}$ pathways $[17,31,32]$. Although a number of these secretory factors may be specific to senescence of certain cell types or the method of senescence induction, the commonly secreted factors are often referred to as the senescence-associated secretory phenotypes [33]. An alternative description of this secretory response would be a DNA damage-induced secretory response, which is not limited to senescent cells and may occur in some circumstances in non-senescent cells such as cancer cells or postmitotic cells [34, 35]. However, since secretory factors may be initiated independent of DNA damage, further research should determine which senescent secretory factors are specific to DNA damage and which are not.

The main molecular pathways of senescence, persistent $\mathrm{DDR}$ and $\mathrm{Rb}$ lead to sustained chromatin remodeling within senescent cells [26, 36, 37]. This stochastic remodeling of chromatin in senescent cells most likely facilitates promiscuous gene expression associated with cell senescence. Promiscuous gene expression is often observed in microarray data and other analysis of gene expression of senescent verses their non-senescent counterparts and appears to also be cell type specific [38-41]. Promiscuous gene expression refers to changes in gene expression not normally associated with nonsenescent counterparts of the same cell type. Chromatin rearrangement would allow access to DNA normally tightly packed and restrict other areas of chromatin that are normally open. It has also been suggested that DNA damage may modulate gene expression by altering the binding capacity of transcription factors [42]. In addition, changes in DNA methylation associated with cell senescence may also contribute to promiscuous gene expression [40, 43]. Therefore, genes that may normally be expressed can be suppressed and genes normally suppressed become expressed.

Cell senescence can thus be defined by three prevalent features which might be associated with a persistent DDR in the majority of cell types: (1) irreversible growth arrest and activation of molecular pathways leading to this arrest, (2) secretion of soluble factors, and (3) promiscuous gene expression. However, it should be emphasized that while different triggers appear to induce a similar senescence response, the molecular differences as a result of the various stimuli are not yet fully understood. The majority of the early work on cell senescence was carried out on fibroblasts in vitro, with a limited understanding of the senescent phenotype of other cell types, especially those linked to age-related pathologies in vivo. Therefore, further investigations are required for detailed characterization of senescent cells in these conditions.

Since cell senescence can be induced in a variety of different cells types and by numerous triggers in different locations within organisms, it is necessary to standardize the set of criteria required to identify senescent cells in tissues. The standard SA- $\beta$-gal staining [44], while indicative of the presence of senescent cells, is not an absolute marker for senescent cell and indicates increased lysosomal b-galactosidase activity [45]. The use of several molecular markers that represent different characteristics of senescent cells is necessary (Fig. 2). Such molecular markers can represent the cell cycle arrest machinery (e.g. p53, p21, p16), lack of cellular proliferation (e.g. lack of BrdU incorporation, Ki67), activation of the DDR (e.g. $\gamma \mathrm{H} 2 \mathrm{AX}$ or p53BP1 foci), expression of secretory factors (e.g. IL-6 and IL-8), the activation of the pathways that regulate the secretory phenotype (e.g. p-p65 or p-p38), the activation of immune surveillance-related genes and possible regulators for their pro-survival response (DCR2, p-Akt, p-Erk). Loss of Lamin B1 in senescent cells has also been suggested to be a marker of cell senescence [46]. The presence of several such markers in addition to the SA- $\beta$-gal should clearly indicate the presence of senescent cells.

\section{Physiological impact of cell senescence in vivo}

\section{Tumor suppression}

While the history of research on cell senescence counts for more than half a century, only in the last 10 years the 


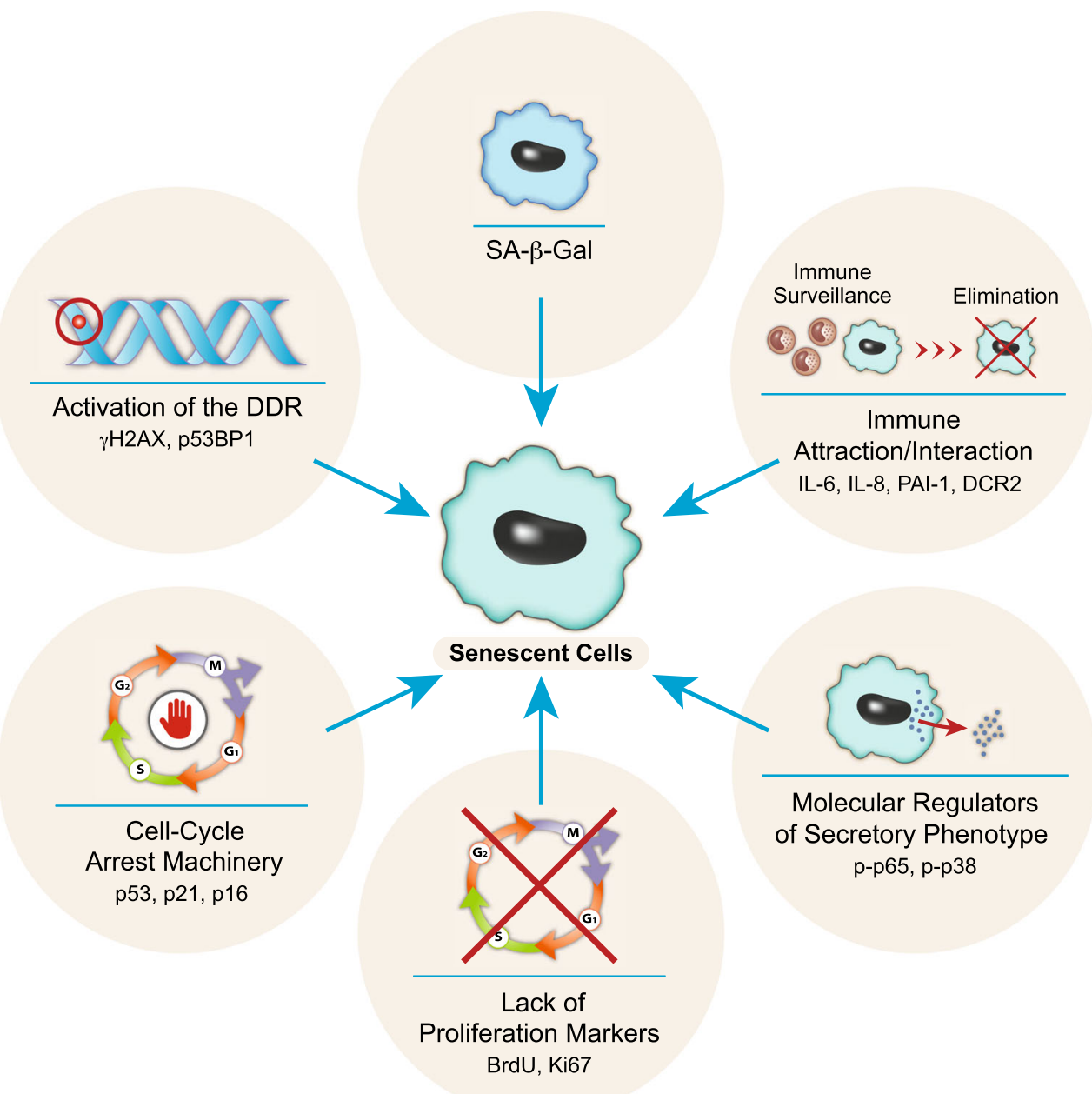

Fig. 2 Identifying senescent cells. The use of several molecular markers that represent different characteristics of cell senescence is necessary for identifying senescent cells. The markers are divided into categories according to their function. A combination of markers representing different categories might increase the validity of the identification functional relevance of cell senescence in vivo was established. The irreversible cell cycle arrest in OIS cells makes it an ideal mechanism to prevent tumor formation following oncogene activation [7], and in the first functional in vivo studies, cell senescence was established as a tumor suppressor mechanism [47-50]. OIS has been shown to be important for preventing lymphoma development and contribute to response to therapy $[47,51]$. Using transgenic mice models to bypass the senescence response to oncogenic N-Ras resulted in the development of invasive $\mathrm{T}$ cell lymphomas, whereas control mice only develop non-lymphoid neoplasia at a much later time point [47]. Another mouse model using inducible $\mathrm{K}$-ras was used to make premalignant lesions that can develop into malignant tumors in lung and pancreas [49]. In these models, biomarkers of cell senescence were predominantly identified in the premalignant lesions but were lost once tumors developed. To investigate OIS in vivo, a number of studies have focused on human nevi (moles), which are benign tumors of melanocytes that frequently harbor oncogenic mutations of BRAF. The congenital nevi stained positive for markers of OIS, but not DNA damage in this instance. Braf ${ }^{\mathrm{E} 600 \mathrm{~V}}$, which is present in the nevi, induced p16(INK4a) expression in growth-arrested melanocytes both in vitro and in situ [50]. In contrast, another study in pre-malignant melanocytic lesions did show the presence of DNA damage foci, primarily located at telomeric regions as well as the p16(INK4a) expression [52]. In addition to activating mutations in oncogenes, cell senescence can be induced as a result of loss of tumor suppressor Pten in the prostate [48]. Therefore, these combined studies clearly demonstrate that cell senescence acts as a potent tumor suppressor mechanism that prevents the development of multiple malignancies. 
Limiting tissue damage

In addition to their tumor suppression function, senescent cells also play a beneficial role in non-cancer pathologies by limiting tissue fibrosis [53]. For instance, tissue damage within the liver stimulates the activation of hepatic stellate cells (HSCs), which hyper-proliferate and secrete extracellular matrix components to form a fibrotic scar. Hyperproliferation of HSCs induces cell senescence leading to a reduction in the secretion of ECM proteins and enhanced secretion of ECM degrading proteins, thereby limiting fibrosis. Senescent HSCs are then eliminated in a timely manner by immune cells such as natural killer (NK) cells. When the mechanisms leading to NK cell-mediated elimination are disabled, fibrosis is increased [54]. In mice lacking molecular components required for induction of cell senescence, HSCs continue to proliferate, depositing ECM components and elevating the fibrotic response [53]. Therefore, induction of senescence in HSCs prevents shortterm tissue damage by limiting fibrosis. In addition to the liver, a similar process occurs during tissue repair within the pancreas by senescent pancreatic stellate cells [55]. In this instance, it was suggested that lymphocytes at the sites of wounds might play a duel-specific role in pancreatic fibrogenesis by triggering both the initiation of wound healing by activating stellate cells and its completion by clearance of senescent stellate cells.

Cell senescence also limits tissue damage at sites of cutaneous wound healing, where secretion of CCN1 induces fibroblast senescence associated with an elevation in the DNA damage response and the activation of p53 and RAC1-NOX1 complex [56]. The expression of anti-fibrotic genes by CCN1-induced senescent cells prevented excess fibrosis, whereas mice that express a senescencedefective CCN1 mutant resulted in elevated fibrosis. CCN1 also appears to play a role in the regression of liver fibrosis through induction of cell senescence in HSCs [57]. Therefore, cell senescence is a mechanism that limits tissue damage in multiple tissues and serves not only to restrain the damage, but also to initiate the repair and return the tissue to its pre-damaged state.

\section{Promoting embryonic development}

In addition to providing a protective role in tumour suppression and tissue damage, senescent cells may also function in embryonic development. It was suggested that cell-cell fusion induced senescence (FIS) might play a physiological function in the placenta, thereby aiding embryonic development [58]. ERVWE1, a fusion protein involved in the formation of the syncytiotrophoblast of the placenta causes cell fusion and induction of cell senescence in both cancer cells and normal fibroblasts [58]. FIS in vitro and in vivo is accompanied by activation of a DDR, p53 and p16(INK4a) dependent pathways. ERVWE1 mediated physiological cell fusion during embryonic development forms the syncytiotrophoblast that serves as the maternal/ fetal interface at the placenta. The question of why the senescence program may be useful in normal placental function remains to be answered. However, it can be suggested that the resistance of senescent cells to apoptosis [59] is necessary to maintain the viability of the syncytiotrophoblast. In addition, secretion of proteases, that are normally associated with senescent cells, may function to maintain feto-placental homeostasis. Placental proteases are required for the metabolism of vasoactive and immunomodulating peptides, thereby controlling the exchange of peptide hormones across the placenta and metabolic breakdown of maternal nutrients [60]. Cytokine production is another feature of senescent cells that may play important roles within the placenta [61]. IL-8, one of the main cytokines secreted by senescent cells, is necessary for normal placental function [62,63]. Cytokine secretion may help regulate placental growth during pregnancy [61] in addition to protecting the fetus from pathological organisms and facilitating interaction with immune cells [62, 64]. Further research is necessary to understand the functional significance of the senescence program in the placenta.

A form of cell senescence associated with development of transient fetal structures has also been recently described $[65,66]$. Developmental senescent cells were located throughout the embryo including at sites of the mesonephros and the endolymphatic sac of the inner ear [65] and the apical ectodermal ridge and the neural roof plate [66]. The authors suggested that senescent cells play an important role instructing tissue growth and organ patterning. In addition, since tissue remodeling is actively occurring during embryogenesis via the elimination of cells through programmed cell death, developmental senescent cells may also function to maintain tissue integrity. However, these cells do not display a DDR and are induced independent of p53 and p16(INK4a) expression. Instead, these cells are dependent upon $\mathrm{p} 21$, regulated via the TGF$\beta / \mathrm{SMAD}$ and PI3K/FOXO pathways. Interestingly, these developmental senescent cells also share an expression signature with OIS [66]. Ongoing research into the role of cell senescence in embryonic development will provide further insights into its physiological function under these circumstances.

\section{Pathological impact of cell senescence}

Paradoxically, while the induction of cell senescence can initially have beneficial effects by preventing 
tumourigenesis and limiting tissue damage, their long-term presence within tissues can potentially promote age-related diseases and potentiate cancer formation [67-71]. There are three main features of senescent cells that allow them to have a detrimental impact on the tissues in which they reside. First, the inability to proliferate alone can potentially impair tissue regeneration, more so if stem or progenitor cells become senescent. Second, cellular dysfunction prevents senescent cells from carrying out their normal physiological functions. Third, and maybe most prominently, by negatively impacting the local microenvironment via cell non-autonomous mechanisms.

\section{Impairment of tissue regeneration}

In response to cell loss through tissue damage, cells can undergo cellular proliferation to generate new tissue. This may be from somatic cells residing within the surrounding tissue, from stem cells residing within the same tissue or from stem cells derived from a distant source, such as the bone marrow [72, 73]. In addition, some mitotic cell types such as satellite cells function to maintain and regenerate post-mitotic cells such as skeletal muscle following damage [74]. Therefore, any loss of replicative potential would impact not only the mitotic fraction of cells, but would also impact the repair of post-mitotic cells. For example, damage to skeletal muscle in normal young mice causes the activation of quiescent satellite cells (adult stem cells), which proliferate and undergo myogenic differentiation required for muscle repair. However, a recent study has shown that in geriatric mice (28-32 months of age), satellite cell activation is impaired and satellite cells instead convert from a pre-senescent state [quiescent cells with high p16(INK4a) expression] to a full senescent state (including a DDR) when stimulated to proliferate in response to injury [29]. As such, the induction of senescent satellite cells with age can impair satellite muscle regeneration. This study suggests that senescent cells may accumulate in late life due to a conversion from quiescence to senescence (termed geroconversion) in response to a requirement for cells to replicate over time to regenerate tissue. In this model, more and more quiescent cells are likely to accumulate DNA damage over the life-time of an organism and are, therefore, more likely to become senescent when induced to proliferate later in life.

The induction of cell senescence in another stem cell compartment, the hematopoietic stem cells, has also been suggested to play a role in reducing stem cells renewal capacity associated with age. The expression of p16(INK4a) was shown to be elevated in hematopoietic stem cells with age, thereby limiting hematopoietic stem cell pools and impairing hematopoietic stem cells repopulation potential [75]. In addition, an age-related increase in p16(INK4a) was shown to reduce islet proliferation associated with an impaired regenerative response, whereas mice lacking p16(INK4a) demonstrated enhanced proliferation and regenerative response [76]. Mice lacking p16(INK4a) were also shown to be partially protected from an age-related decline in the self-renewal potential of neuronal progenitors in the subventricular zone and during neurogenesis in the olfactory bulb [77]. Therefore, p16(INK4a) mediated senescence contributes to the decline in a potential of stem and progenitor cells to regenerate tissues.

\section{Cellular dysfunction}

A negative consequence of promiscuous gene expression in senescent cells is impairment in cellular function, the inability of cells to carry out their designated normal processes. As a result, the accumulation of these dysfunctional cells most likely leads to tissue dysfunction which compromises tissue structure and function, promoting disease. For example, a study using Klotho-deficient mice, which exhibit an accelerated aging-like phenotype, investigated whether preventing cell senescence improves health span in these mice [78]. Plasminogen activator inhibitor-1 (PAI1) is elevated in Klotho-deficient mice and is a known regulator of cell senescence [78, 79]. Klotho-deficient mice deficient in PAI-1 was reported to delay the induction of cell senescence, extending median lifespan and preserving organ structure and function. Another example of senescent cells that can no longer undertake their normal function might include senescent pancreatic beta cells that have impaired insulin release during diabetes [80] and senescent vascular endothelial cells that display decreased activity of nitric oxide synthase (NOS) [81]. NOS is important for the production of nitric oxide (NO) required for maintaining vascular homeostasis and a decrease in NO production is associated with increased risk of cardiovascular disease [82]. Therefore, understanding of the differences in the phenotype of senescent cells of different cell types in relation to their in vivo function is required to better understand mechanisms of disease development.

Impact on the microenvironment

Senescent cells have the potential to negatively impact their surrounding microenvironment by secreting soluble factors such as cytokines, growth factors and proteases. A number of studies have demonstrated that soluble factors secreted from senescent cells can facilitate cellular proliferation and tumorigenesis in neighboring cells [83-87]. However, these secretory factors might also contribute to tumor-suppressive macrophage polarization and reinforce cell cycle arrest in normal cells, limiting their proliferative 
potential [31, 88, 89]. However, while the secretion of soluble factors by senescent cells has been the primary focus in understanding how senescent cells promote tumorigenesis, it appears that direct cell contact of senescent cells with neighboring cells may be a more potent mechanism in promoting tumorigenesis [83]. Therefore, other potential mechanisms for promoting tumorigenesis, particularly those involving direct cell contact should be considered in further studies.

Proteases, such as matrix metalloproteinases (MMPs) and collagenases, secreted by senescent cells are able to cause degradation of the extracellular matrix (ECM) [9092]. ECM remodeling is an important mechanism in the regulation of cell differentiation [93], maintenance of stem cells niches [94], angiogenesis [95], bone remodeling [96] and wound healing [97]. Therefore, it is not difficult to envision how ECM destruction can compromise the functional integrity of the surrounding tissue, promoting disease. An interesting study has demonstrated that when replicative senescent fibroblasts are grown on ECM produced by proliferating cells, they revert back to a "youthful" phenotype [98]. This study thus demonstrates the importance of maintaining ECM structure for regulating cellular function.

It also appears that cells can develop a cell-type exclusive senescent phenotype that could also compromise tissue function and promote disease. When vascular smooth muscle cells (VSMCs) undergo RS they appear to partially trans-differentiate into an osteoblastic, pro-calcificatory phenotype $[41,99]$. It was suggested and later shown that secretory factors from senescent VSMCs may play a role in the development of this pro-calcificatory phenotype via an autocrine/paracrine response [100, 101]. It is also likely that secretory factors specific to senescent VSMCs also play a role in the development of this phenotype. Vascular calcification is a major contributor of cardiovascular disease (CVD), suggesting that senescent VSMCs may play an active role in CVD pathophysiology. Interestingly, delaying cell senescence in an accelerated aging mouse model resulted in significant reduction in ectopic calcification [78]. Understanding how different senescent cell types specifically respond to their secretory phenotype may provide further insight into the pathophysiology of various diseases.

\section{Further evidence for the presence of senescent cells in vivo}

While the majority of studies on RS are focused on in vitro studies, evidence for RS in vivo has also been provided. RS cells were detected within livers with chronic hepatitis, cirrhosis and hepatocellular carcinoma as determined by
SA- $\beta$-Gal staining and measurement of telomere length [102, 103]. Moreover, mice with decreased telomere length were more susceptible for induction of liver cirrhosis [104], suggesting that telomere shortening and induction of cell senescence can contribute to pathological conditions.

Cell senescence has also been shown to be elevated within the skin of aging primates [105]. This study showed that the number of dermal fibroblasts displaying biomarkers of cell senescence such as telomere damage, p16(INK4a) expression and a DDR is elevated in aging baboons. A number of studies have also reported the presence of senescent cells in vivo without clear differences in telomere length. For example, cell senescence in rat kidneys increases with age, associated with an elevation p16(INK4a), but no significant difference in telomere length was observed [106]. Crypt enterocytes within the intestine appear to become senescent with age independent of telomere shortening, associated with elevated DNA damage as determined by $\gamma \mathrm{H} 2 \mathrm{~A} . \mathrm{X}$ immunocytochemistry [107]. Brain tissue from aged individuals and patients with Alzheimer's disease (AD) was used to investigate astrocyte senescence [108]. Using p16(INK4a) and matrix metalloproteinase-1 (MMP-1) expression as a biomarker of cell senescence, an elevation in astrocyte senescence was observed compared to fetal controls and non-AD adult controls. An earlier in vitro study by the same group also demonstrated that astrocyte senescence could also be triggered by oxidative stress [109]. Further functional studies using in vivo models will provide a better understanding of the possible role of cell senescence in aging and age-related diseases.

\section{Immune surveillance of senescent cells}

The ability of senescent cells to trigger an innate immune response via the up-regulation of pro-inflammatory cytokines was first suggested to play a role in limiting tumorigenesis [110]. This immune response was later shown to be important in the elimination of senescent stellate cells during liver damage [53]. In natural killer (NK) cell-mediated cytotoxicity, NK cells identify senescent cells by the presence of NKG2D ligands on the membrane of senescent cells [53, 111, 112]. The presentation of these ligands on senescent cells might be mediated by a DDR, which was previously shown to induce their expression [113]. In particular, it appears that the ATMATR pathway is important for the up-regulation of NKG2D ligands in response to stress [111]. NK cell-induced cytotoxicity of senescent cells is mediated by granule exocytosis and perforin-mediated death rather than death receptor-induced apoptosis [54]. The perforin-mediated cytotoxicity decreases in humans with age [114], and 
might, therefore, contribute to accumulation of senescent cells in the organism during aging and in age-related diseases. As discussed, senescent cells are known to accumulate with age and in disease states, suggesting that senescent cells may be evading immune surveillance or their rate of accumulation is greater than the rate of removal or both. It has been advocated that the accumulation of senescent cells with age might be the consequence of an impaired aging immune system [70, 115]. In fact, immune cells can also become senescent [116, 117] and these changes may contribute to impaired elimination of senescent cells. Therefore, strategies to restore an aging immune system are a compelling approach for the elimination of senescent cells and for promoting an increased health span.

A recent study has shown that senescent HSCs can be eliminated by another component of the innate immune system, the M1-like macrophages during liver damage and tumorigenesis in the liver [89]. Secretory factors from senescent HSCs were shown to aid the elimination of these cells by macrophages. In contrast, cells that could not become senescent due to deletion of p53 and were not targeted by macrophages. Therefore, the innate immune system appears to be an initial early barrier that regulates the presence of senescent cells in physiological conditions such as in wound healing.

The elimination of senescent cells by the adaptive immune system has also been demonstrated [118]. OIS hepatocytes were shown to secrete cytokines to evoke an immune response leading to the elimination of senescent cells by $\mathrm{CD} 4(+) \mathrm{T}$ cells, a process which required the action of macrophages. The elimination of senescent hepatocytes was required to prevent the development of liver cancer. This study mentions the attraction of $\mathrm{T}$ cells by soluble factors but not the mechanism of senescent cell recognition, an area of research that still needs to be explored. However, there is some indication that RS cells may up-regulate MHC1 expression, possibly via p53 [119, 120]. It can be speculated that $\mathrm{MHC} 1$ proteins in senescent cells may function to display senescence-associated antigens similar to cancer cells [121], allowing recognition and elimination by cytotoxic $\mathrm{T}$ cells. Further research will provide multiple insights into the mechanisms and consequences of the interaction of senescent cells with the immune system.

\section{Persistence of senescent cells}

When cells become senescent in vitro they often become resistant to apoptotic stimuli in comparison to proliferating cells [59, 122]. Although the molecular mechanisms governing this pro-survival response has yet to be fully elucidated, the inability of senescent cells to stabilize p53 in response to further insults of DNA damage appears to play a role in preventing apoptosis [123]. It can be speculated that if immune cells are necessary for eliminating senescent cells, the pro-survival phenotype of senescent cells may function to favor such elimination. In conjunction with regulating immune ligands and the secretory phenotype, persistent activation of the DDR, particularly double strand breaks (DSBs), may also promote a prosurvival response to facilitate DNA repair [124]. However, if senescent cells are not removed by the immune system, this pro-survival phenotype inadvertently promotes their persistence in tissues. Alternatively, the pro-survival phenotype of senescent cells may be an adaptive response mediated by stresses within the microenvironment to facilitate protection from further stress.

The question still arises as to why senescent cells may favor removal by the immune system rather than undergoing programmed cell death. One plausible explanation could be related to the potential function of senescent cells during cellular repair following tissue damage. During wound healing, senescent cells most likely play a positive role by (1) secreting chemoattractants that recruit and activate immune cells to the site of injury, (2) secrete growth factors to stimulate cellular proliferation required for cellular replacement and protein synthesis and (3) the secretion of proteases to debride damaged tissue. In addition, senescent cells may help to preserve tissue integrity during wound healing. If cells underwent apoptosis, the integrity may be lost. Induction of senescence and not apoptosis preserves tissue structure until such time that non-resident cells from other sources, such as stem cells are present to repopulate the tissue with functional cells. In an orchestrated response, senescent cells would be subsequently eliminated by the immune system when no longer required.

If this is indeed the case then the induction of cell senescence, independent of physical wounding (e.g. RS, OIS, SIPS), may evoke a wound healing-like response. However, it is not known whether the induction of cell senescence in a single cell provides enough stimuli to attract immune cells for its elimination. We have suggested above that senescent cells may accumulate as a result of a failure to eliminate them by an aging immune system, but an additional explanation is that they accumulate with age because a single senescent cell is insufficient to stimulate an immune response on its own.

\section{Concluding remarks}

The persistence and accumulation of senescent cells have been shown to potentially play a role in the pathophysiology 

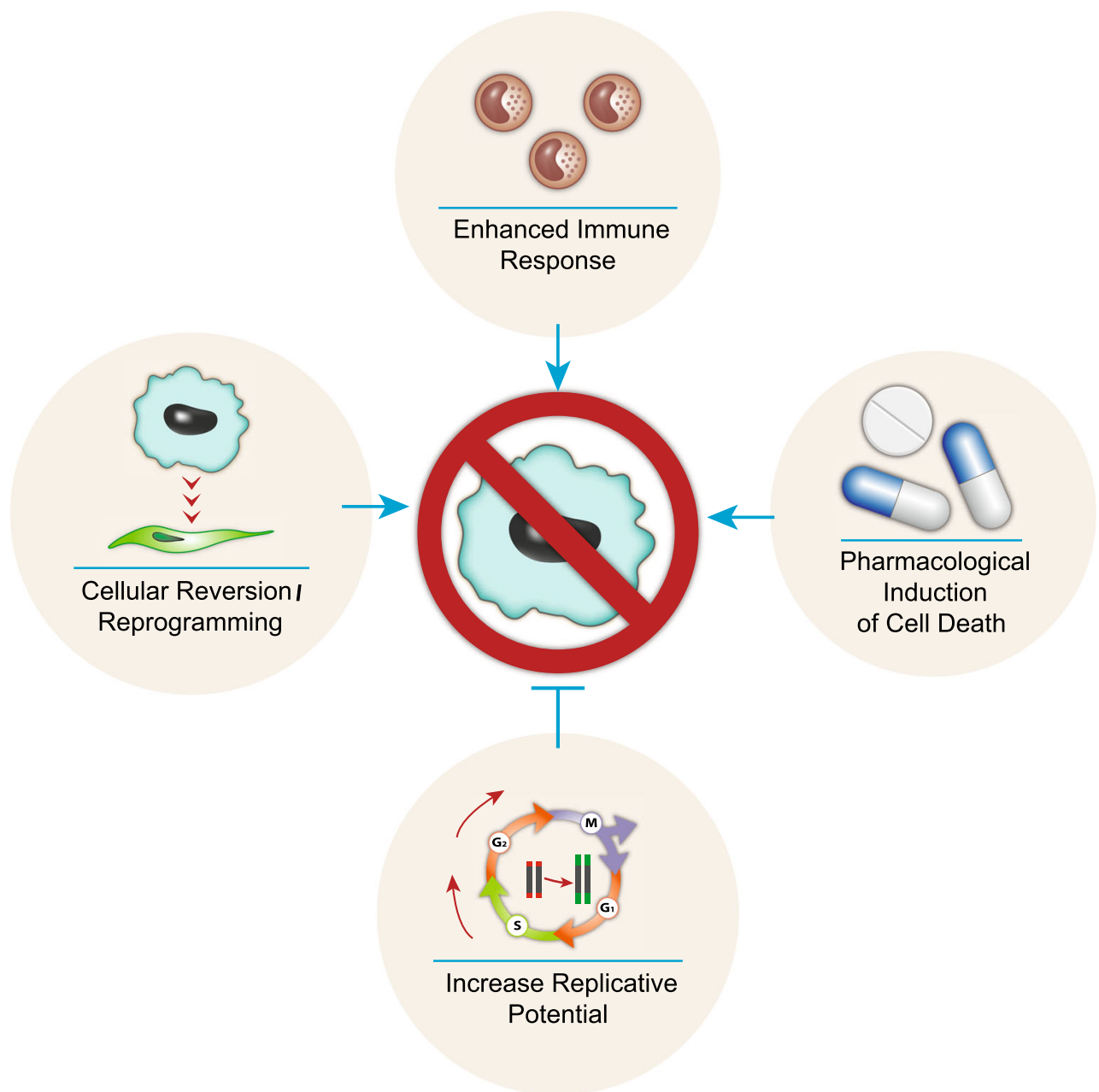

Fig. 3 Therapeutic strategies for preventing and eliminating senescent cells. The diagram summarizes the proposed strategies to reduce the presence of senescent cells. These strategies include: extending telomere length with the use of telomerase activators would enhance the replicative lifespan of cells and prevent replicative senescence. Senescent cells could potentially be reverted/reprogrammed back to

of aging and age-related disease. In fact, various disorders associated with accelerated aging such as Hutchinson-Gilford progeria and Werner syndrome have been linked with senescent cells $[125,126]$. Therefore, the elimination of senescent cells from tissues has the potential to increase health span and possibly even lifespan. For example, it was recently demonstrated that the elimination of p16-expressing cells in a transgenic mouse model delays age-associated disorders [127]. As such, there are a number of therapeutic avenues of research that have the potential to eliminate senescent cells or prevent their accumulation (Fig. 3). First, telomerase activators could be used to extend telomere length, thereby extending the replicative capacity of cells and preventing RS. Second, cellular reprogramming refers to the potential of reverting senescent cells back to their normal functioning state. Alternatively, if quiescent cells inflicted their functional state. Rejuvenation of an age-impaired immune system may enhance removal of senescent cells. Alternatively, enhancing immune recognition of senescent cells may also be an option. Therapeutic compounds can be developed which specifically target and induce cell death in senescent cells

with DNA damage convert to senescence when stimulated to proliferate, then eliminating such damage may prevent this conversion. Third, if senescent cells indeed accumulate due to failure of removal by an aging immune system, then enhancing the immune response to senescent cells may improve their elimination. Finally, identification of pharmacological compounds that can specifically induce programmed cell death in senescent cells will provide an effective means for elimination of senescence cells regardless the reason of their presence. However, the potential use of future pharmacological compounds should be taken with caution, since senescent cells also play a beneficial role during wound healing. Prematurely eliminating senescent cells during tissue damage may impair the wound response. In fact, it can be speculated that a trade-off may exist between senescent cell removal and wound healing, 
whereby enhanced senescent cell removal (and possibly slowing aging) results in a slower healing process (and increase risk of infectious disease). Future research will show if pharmacological elimination of senescent cells is a good avenue for treatment of age-related disorders and health span extension.

Acknowledgments We thank H. Gal and A. Biran for reading our manuscript and helpful suggestions, all members of Krizhanovsky laboratory for great discussions. V. K. was supported by Grants from Israel Science Foundation, European Research Council and Marie Curie IRG Grants under EU FP7 program and DKFZ-MOST program. V. K. is an incumbent of The Karl and Frances Korn Career Development Chair in Life Sciences.

Open Access This article is distributed under the terms of the Creative Commons Attribution License which permits any use, distribution, and reproduction in any medium, provided the original author(s) and the source are credited.

\section{References}

1. Hayflick L, Moorhead PS (1961) The serial cultivation of human diploid cell strains. Exp Cell Res 25:585-621

2. Allsopp RC, Harley CB (1995) Evidence for a critical telomere length in senescent human fibroblasts. Exp Cell Res 219(1):130-136. doi:10.1006/excr.1995.1213

3. Harley CB, Futcher AB, Greider CW (1990) Telomeres shorten during ageing of human fibroblasts. Nature 345(6274):458-460. doi:10.1038/345458a0

4. Jpma IAS, Greider CW (2003) Short telomeres induce a DNA damage response in Saccharomyces cerevisiae. Mol Biol Cell 14(3):987-1001. doi:10.1091/mbc.02-04-0057

5. Allsopp RC (1996) Models of initiation of replicative senescence by loss of telomeric DNA. Exp Gerontol 31(1-2):235-243 (pii):0531-5565(95)02008-X

6. Bodnar AG, Ouellette M, Frolkis M, Holt SE, Chiu CP, Morin GB, Harley CB, Shay JW, Lichtsteiner S, Wright WE (1998) Extension of life-span by introduction of telomerase into normal human cells. Science 279(5349):349-352

7. Serrano M, Lin AW, McCurrach ME, Beach D, Lowe SW (1997) Oncogenic ras provokes premature cell senescence associated with accumulation of p53 and p16INK4a. Cell 88(5):593-602

8. Zhu J, Woods D, McMahon M, Bishop JM (1998) Senescence of human fibroblasts induced by oncogenic Raf. Genes Dev 12(19):2997-3007

9. Nelson DM, McBryan T, Jeyapalan JC, Sedivy JM, Adams PD (2014) A comparison of oncogene-induced senescence and replicative senescence: implications for tumor suppression and aging. Age (Dordr) 36(3):9637. doi:10.1007/s11357-014-9637-0

10. Bartkova J, Rezaei N, Liontos M, Karakaidos P, Kletsas D, Issaeva N, Vassiliou LV, Kolettas E, Niforou K, Zoumpourlis VC, Takaoka M, Nakagawa H, Tort F, Fugger K, Johansson F, Sehested M, Andersen CL, Dyrskjot L, Orntoft T, Lukas J, Kittas C, Helleday T, Halazonetis TD, Bartek J, Gorgoulis VG (2006) Oncogene-induced senescence is part of the tumorigenesis barrier imposed by DNA damage checkpoints. Nature 444(7119):633-637

11. Di Micco R, Fumagalli M, Cicalese A, Piccinin S, Gasparini P, Luise C, Schurra C, Garre M, Nuciforo PG, Bensimon A,
Maestro R, Pelicci PG, d'Adda di Fagagna F (2006) Oncogeneinduced senescence is a DNA damage response triggered by DNA hyper-replication. Nature 444(7119):638-642

12. Mallette FA, Gaumont-Leclerc MF, Ferbeyre G (2007) The DNA damage signaling pathway is a critical mediator of oncogene-induced senescence. Genes Dev 21(1):43-48

13. Moiseeva O, Bourdeau V, Roux A, Deschenes-Simard X, Ferbeyre G (2009) Mitochondrial dysfunction contributes to oncogene-induced senescence. Mol Cell Biol 29(16):4495-4507. doi:10.1128/MCB.01868-08

14. Rai P, Young JJ, Burton DG, Giribaldi MG, Onder TT, Weinberg RA (2011) Enhanced elimination of oxidized guanine nucleotides inhibits oncogenic RAS-induced DNA damage and premature senescence. Oncogene 30(12):1489-1496. doi:10. 1038/onc. 2010.520

15. Deschenes-Simard X, Gaumont-Leclerc MF, Bourdeau V, Lessard F, Moiseeva O, Forest V, Igelmann S, Mallette FA, SabaEl-Leil MK, Meloche S, Saad F, Mes-Masson AM, Ferbeyre G (2013) Tumor suppressor activity of the ERK/MAPK pathway by promoting selective protein degradation. Genes Dev 27(8):900-915. doi:10.1101/gad.203984.112

16. Palmero I, Pantoja C, Serrano M (1998) p19ARF links the tumour suppressor p53 to Ras. Nature 395(6698):125-126. doi:10.1038/25870

17. Freund A, Patil CK, Campisi J (2011) p38MAPK is a novel DNA damage response-independent regulator of the senescenceassociated secretory phenotype. EMBO J 30(8):1536-1548. doi:10.1038/emboj.2011.69

18. Toussaint O, Medrano EE, von Zglinicki T (2000) Cellular and molecular mechanisms of stress-induced premature senescence (SIPS) of human diploid fibroblasts and melanocytes. Exp Gerontol 35(8):927-945

19. Dierick JF, Eliaers F, Remacle J, Raes M, Fey SJ, Larsen PM, Toussaint O (2002) Stress-induced premature senescence and replicative senescence are different phenotypes, proteomic evidence. Biochem Pharmacol 64(5-6):1011-1017

20. Wei YH, Lee HC (2002) Oxidative stress, mitochondrial DNA mutation, and impairment of antioxidant enzymes in aging. Exp Biol Med 227(9):671-682

21. Opresko PL, Mason PA, Podell ER, Lei M, Hickson ID, Cech TR, Bohr VA (2005) POT1 stimulates RecQ helicases WRN and BLM to unwind telomeric DNA substrates. J Biol Chem 280(37):32069-32080. doi:10.1074/jbc.M505211200

22. Perez VI, Van Remmen H, Bokov A, Epstein CJ, Vijg J, Richardson A (2009) The overexpression of major antioxidant enzymes does not extend the lifespan of mice. Aging Cell 8(1):73-75. doi:10.1111/j.1474-9726.2008.00449.x

23. Rodier F, Coppe JP, Patil CK, Hoeijmakers WA, Munoz DP, Raza SR, Freund A, Campeau E, Davalos AR, Campisi J (2009) Persistent DNA damage signalling triggers senescence-associated inflammatory cytokine secretion. Nat Cell Biol 11(8):973-979

24. Vaziri H, West MD, Allsopp RC, Davison TS, Wu YS, Arrowsmith CH, Poirier GG, Benchimol S (1997) ATM-dependent telomere loss in aging human diploid fibroblasts and DNA damage lead to the post-translational activation of p53 protein involving poly(ADP-ribose) polymerase. EMBO J 16(19):6018-6033

25. Robles SJ, Adami GR (1998) Agents that cause DNA double strand breaks lead to p16INK4a enrichment and the premature senescence of normal fibroblasts. Oncogene 16(9):1113-1123. doi:10.1038/sj.onc.1201862

26. Narita M, Nunez S, Heard E, Narita M, Lin AW, Hearn SA, Spector DL, Hannon GJ, Lowe SW (2003) Rb-mediated heterochromatin formation and silencing of E2F target genes during cellular senescence. Cell 113(6):703-716 
27. Beausejour CM, Krtolica A, Galimi F, Narita M, Lowe SW, Yaswen P, Campisi J (2003) Reversal of human cellular senescence: roles of the p53 and p16 pathways. EMBO J 22(16):4212-4222

28. Burton DG, Giribaldi MG, Munoz A, Halvorsen K, Patel A, Jorda M, Perez-Stable C, Rai P (2013) Androgen deprivationinduced senescence promotes outgrowth of androgen-refractory prostate cancer cells. PLoS One 8(6):e68003. doi:10.1371/ journal.pone.0068003

29. Sousa-Victor P, Gutarra S, Garcia-Prat L, Rodriguez-Ubreva J, Ortet L, Ruiz-Bonilla V, Jardi M, Ballestar E, Gonzalez S, Serrano AL, Perdiguero E, Munoz-Canoves P (2014) Geriatric muscle stem cells switch reversible quiescence into senescence. Nature 506(7488):316-321. doi:10.1038/nature13013

30. Blagosklonny MV (2012) Cell cycle arrest is not yet senescence, which is not just cell cycle arrest: terminology for TOR-driven aging. Aging 4(3):159-165

31. Acosta JC, O'Loghlen A, Banito A, Guijarro MV, Augert A, Raguz S, Fumagalli M, Da Costa M, Brown C, Popov N, Takatsu Y, Melamed J, d'Adda di Fagagna F, Bernard D, Hernando E, Gil J (2008) Chemokine signaling via the CXCR2 receptor reinforces senescence. Cell 133(6):1006-1018. doi:10. 1016/j.cell.2008.03.038

32. Chien Y, Scuoppo C, Wang X, Fang X, Balgley B, Bolden JE, Premsrirut P, Luo W, Chicas A, Lee CS, Kogan SC, Lowe SW (2011) Control of the senescence-associated secretory phenotype by NF-\{kappa\}B promotes senescence and enhances chemosensitivity. Genes Dev 25(20):2125-2136. doi:10.1101/ gad.17276711

33. Coppe JP, Patil CK, Rodier F, Sun Y, Munoz DP, Goldstein J, Nelson PS, Desprez PY, Campisi J (2008) Senescence-associated secretory phenotypes reveal cell-nonautonomous functions of oncogenic RAS and the p53 tumor suppressor. PLoS Biol 6(12):2853-2868

34. Gilbert LA, Hemann MT (2010) DNA damage-mediated induction of a chemoresistant niche. Cell 143(3):355-366. doi:10.1016/j.cell.2010.09.043

35. Jurk D, Wang C, Miwa S, Maddick M, Korolchuk V, Tsolou A, Gonos ES, Thrasivoulou C, Saffrey MJ, Cameron K, von Zglinicki T (2012) Postmitotic neurons develop a p21-dependent senescence-like phenotype driven by a DNA damage response. Aging Cell 11(6):996-1004. doi:10.1111/j.1474-9726.2012. 00870.x

36. Narita M, Narita M, Krizhanovsky V, Nunez S, Chicas A, Hearn SA, Myers MP, Lowe SW (2006) A novel role for high-mobility group a proteins in cellular senescence and heterochromatin formation. Cell 126(3):503-514

37. Ye X, Zerlanko B, Kennedy A, Banumathy G, Zhang R, Adams PD (2007) Downregulation of Wnt signaling is a trigger for formation of facultative heterochromatin and onset of cell senescence in primary human cells. Mol Cell 27(2):183-196

38. Shelton DN, Chang E, Whittier PS, Choi D, Funk WD (1999) Microarray analysis of replicative senescence. Curr Biol 9(17):939-945

39. Zhang H, Pan KH, Cohen SN (2003) Senescence-specific gene expression fingerprints reveal cell-type-dependent physical clustering of up-regulated chromosomal loci. Proc Natl Acad Sci USA 100(6):3251-3256. doi:10.1073/pnas.2627983100

40. Bahar R, Hartmann CH, Rodriguez KA, Denny AD, Busuttil RA, Dolle ME, Calder RB, Chisholm GB, Pollock BH, Klein CA, Vijg J (2006) Increased cell-to-cell variation in gene expression in ageing mouse heart. Nature 441(7096):1011-1014. doi:10.1038/ nature 04844

41. Burton DG, Giles PJ, Sheerin AN, Smith SK, Lawton JJ, Ostler EL, Rhys-Williams W, Kipling D, Faragher RG (2009) Microarray analysis of senescent vascular smooth muscle cells: a link to atherosclerosis and vascular calcification. Exp Gerontol 44(10):659-665. doi:10.1016/j.exger.2009.07.004

42. Rose J, Soder S, Skhirtladze C, Schmitz N, Gebhard PM, Sesselmann S, Aigner T (2012) DNA damage, discoordinated gene expression and cellular senescence in osteoarthritic chondrocytes. Osteoarthr Cartil 20(9):1020-1028. doi:10.1016/j.joca. 2012.05.009

43. Cruickshanks HA, McBryan T, Nelson DM, Vanderkraats ND, Shah PP, van Tuyn J, Singh Rai T, Brock C, Donahue G, Dunican DS, Drotar ME, Meehan RR, Edwards JR, Berger SL, Adams PD (2013) Senescent cells harbour features of the cancer epigenome. Nat Cell Biol 15(12):1495-1506. doi:10.1038/ncb2879

44. Dimri GP, Lee X, Basile G, Acosta M, Scott G, Roskelley C, Medrano EE, Linskens M, Rubelj I, Pereira-Smith O, Peacocke M, Campisi J (1995) A biomarker that identifies senescent human cells in culture and in aging skin in vivo. Proc Natl Acad Sci USA 92(20):9363-9367

45. Lee BY, Han JA, Im JS, Morrone A, Johung K, Goodwin EC, Kleijer WJ, DiMaio D, Hwang ES (2006) Senescence-associated beta-galactosidase is lysosomal beta-galactosidase. Aging Cell 5(2):187-195. doi:10.1111/j.1474-9726.2006.00199.x

46. Freund A, Laberge RM, Demaria M, Campisi J (2012) Lamin B1 loss is a senescence-associated biomarker. Mol Biol Cell 23(11):2066-2075. doi:10.1091/mbc.E11-10-0884

47. Braig M, Lee S, Loddenkemper C, Rudolph C, Peters AH, Schlegelberger B, Stein H, Dorken B, Jenuwein T, Schmitt CA (2005) Oncogene-induced senescence as an initial barrier in lymphoma development. Nature 436(7051):660-665

48. Chen Z, Trotman LC, Shaffer D, Lin HK, Dotan ZA, Niki M, Koutcher JA, Scher HI, Ludwig T, Gerald W, Cordon-Cardo C, Pandolfi PP (2005) Crucial role of p53-dependent cellular senescence in suppression of Pten-deficient tumorigenesis. Nature 436(7051):725-730

49. Collado M, Gil J, Efeyan A, Guerra C, Schuhmacher AJ, Barradas M, Benguria A, Zaballos A, Flores JM, Barbacid M, Beach D, Serrano M (2005) Tumour biology: senescence in premalignant tumours. Nature 436(7051):642

50. Michaloglou C, Vredeveld LC, Soengas MS, Denoyelle C, Kuilman T, van der Horst CM, Majoor DM, Shay JW, Mooi WJ, Peeper DS (2005) BRAFE600-associated senescence-like cell cycle arrest of human naevi. Nature 436(7051):720-724

51. Schmitt CA, Fridman JS, Yang M, Lee S, Baranov E, Hoffman RM, Lowe SW (2002) A senescence program controlled by p53 and p16INK4a contributes to the outcome of cancer therapy. Cell 109(3):335-346

52. Suram A, Kaplunov J, Patel PL, Ruan H, Cerutti A, Boccardi V, Fumagalli M, Di Micco R, Mirani N, Gurung RL, Hande MP, d'Adda di Fagagna F, Herbig U (2012) Oncogene-induced telomere dysfunction enforces cellular senescence in human cancer precursor lesions. EMBO J 31(13):2839-2851. doi:10. 1038/emboj.2012.132

53. Krizhanovsky V, Yon M, Dickins RA, Hearn S, Simon J, Miething C, Yee H, Zender L, Lowe SW (2008) Senescence of activated stellate cells limits liver fibrosis. Cell 134(4):657-667

54. Sagiv A, Biran A, Yon M, Simon J, Lowe SW, Krizhanovsky V (2013) Granule exocytosis mediates immune surveillance of senescent cells. Oncogene 32(15):1971-1977. doi:10.1038/Onc. 2012.206

55. Fitzner B, Muller S, Walther M, Fischer M, Engelmann R, Muller-Hilke B, Putzer BM, Kreutzer M, Nizze H, Jaster R (2012) Senescence determines the fate of activated rat pancreatic stellate cells. J Cell Mol Med. doi:10.1111/j.1582-4934. 2012.01573.x

56. Jun JI, Lau LF (2010) The matricellular protein CCN1 induces fibroblast senescence and restricts fibrosis in cutaneous wound healing. Nat Cell Biol 12(7):676-685. doi:10.1038/ncb2070 
57. Kim KH, Chen CC, Monzon RI, Lau LF (2013) Matricellular protein $\mathrm{CCN} 1$ promotes regression of liver fibrosis through induction of cellular senescence in hepatic myofibroblasts. Mol Cell Biol 33(10):2078-2090. doi:10.1128/MCB.00049-13

58. Chuprin A, Gal H, Biron-Shental T, Biran A, Amiel A, Rozenblatt S, Krizhanovsky V (2013) Cell fusion induced by ERVWE1 or measles virus causes cellular senescence. Genes Dev 27(21):2356-2366. doi:10.1101/gad.227512.113

59. Wang E (1995) Senescent human fibroblasts resist programmed cell death, and failure to suppress bcl 2 is involved. Cancer Res 55(11):2284-2292

60. Mizutani S, Tomoda Y (1996) Effects of placental proteases on maternal and fetal blood pressure in normal pregnancy and preeclampsia. Am J Hypertens 9(6):591-597

61. Bowen JM, Chamley L, Keelan JA, Mitchell MD (2002) Cytokines of the placenta and extra-placental membranes: roles and regulation during human pregnancy and parturition. Placenta 23(4):257-273. doi:10.1053/plac.2001.0782

62. Shimoya K, Matsuzaki N, Taniguchi T, Kameda T, Koyama M, Neki R, Saji F, Tanizawa O (1992) Human placenta constitutively produces interleukin- 8 during pregnancy and enhances its production in intrauterine infection. Biol Reprod 47(2):220-226

63. Jovanovic M, Stefanoska I, Radojcic L, Vicovac L (2010) Interleukin-8 (CXCL8) stimulates trophoblast cell migration and invasion by increasing levels of matrix metalloproteinase (MMP)2 and MMP9 and integrins alpha5 and beta1. Reproduction 139(4):789-798. doi:10.1530/REP-09-0341

64. Hanna J, Wald O, Goldman-Wohl D, Prus D, Markel G, Gazit R, Katz G, Haimov-Kochman R, Fujii N, Yagel S, Peled A, Mandelboim O (2003) CXCL12 expression by invasive trophoblasts induces the specific migration of CD16- human natural killer cells. Blood 102(5):1569-1577. doi:10.1182/ blood-2003-02-0517

65. Munoz-Espin D, Canamero M, Maraver A, Gomez-Lopez G, Contreras J, Murillo-Cuesta S, Rodriguez-Baeza A, Varela-Nieto I, Ruberte J, Collado M, Serrano M (2013) Programmed cell senescence during mammalian embryonic development. Cell 155(5):1104-1118. doi:10.1016/j.cell.2013.10.019

66. Storer M, Mas A, Robert-Moreno A, Pecoraro M, Ortells MC, Di Giacomo V, Yosef R, Pilpel N, Krizhanovsky V, Sharpe J, Keyes WM (2013) Senescence is a developmental mechanism that contributes to embryonic growth and patterning. Cell 155(5):1119-1130. doi:10.1016/j.cell.2013.10.041

67. Faragher RG, Kipling D (1998) How might replicative senescence contribute to human ageing? BioEssays 20(12):985-991. doi:10.1002/(SICI)1521-1878(199812)20:12<985:AID$\mathrm{BIES} 4>3.0 . \mathrm{CO} ; 2-\mathrm{A}$

68. Campisi J (2005) Senescent cells, tumor suppression, and organismal aging: good citizens, bad neighbors. Cell 120(4):513-522

69. Collado M, Blasco MA, Serrano M (2007) Cellular senescence in cancer and aging. Cell 130(2):223-233

70. Burton DG (2009) Cellular senescence, ageing and disease. Age (Dordr) 31(1):1-9. doi:10.1007/s11357-008-9075-y

71. Kuilman T, Michaloglou C, Mooi WJ, Peeper DS (2010) The essence of senescence. Genes Dev 24(22):2463-2479. doi:10. 1101/gad.1971610

72. Barker N, Bartfeld S, Clevers H (2010) Tissue-resident adult stem cell populations of rapidly self-renewing organs. Cell Stem Cell 7(6):656-670. doi:10.1016/j.stem.2010.11.016

73. Wu Y, Chen L, Scott PG, Tredget EE (2007) Mesenchymal stem cells enhance wound healing through differentiation and angiogenesis. Stem Cells 25(10):2648-2659. doi:10.1634/stemcells. 2007-0226

74. Collins CA, Olsen I, Zammit PS, Heslop L, Petrie A, Partridge TA, Morgan JE (2005) Stem cell function, self-renewal, and behavioral heterogeneity of cells from the adult muscle satellite cell niche. Cell 122(2):289-301. doi:10.1016/j.cell.2005.05.010

75. Janzen V, Forkert R, Fleming HE, Saito Y, Waring MT, Dombkowski DM, Cheng T, DePinho RA, Sharpless NE, Scadden DT (2006) Stem-cell ageing modified by the cyclindependent kinase inhibitor p16INK4a. Nature 443(7110):421-426

76. Krishnamurthy J, Ramsey MR, Ligon KL, Torrice C, Koh A, Bonner-Weir S, Sharpless NE (2006) p16INK4a induces an agedependent decline in islet regenerative potential. Nature 443(7110):453-457

77. Molofsky AV, Slutsky SG, Joseph NM, He S, Pardal R, Krishnamurthy J, Sharpless NE, Morrison SJ (2006) Increasing p16INK4a expression decreases forebrain progenitors and neurogenesis during ageing. Nature 443(7110):448-452

78. Eren M, Boe AE, Murphy SB, Place AT, Nagpal V, MoralesNebreda L, Urich D, Quaggin SE, Budinger GR, Mutlu GM, Miyata T, Vaughan DE (2014) PAI-1-regulated extracellular proteolysis governs senescence and survival in Klotho mice. Proc Natl Acad Sci USA. doi:10.1073/pnas.1321942111

79. Kortlever RM, Higgins PJ, Bernards R (2006) Plasminogen activator inhibitor- 1 is a critical downstream target of p53 in the induction of replicative senescence. Nat Cell Biol 8(8):877-884. doi:10.1038/ncb1448

80. Sone H, Kagawa Y (2005) Pancreatic beta cell senescence contributes to the pathogenesis of type 2 diabetes in high-fat diet-induced diabetic mice. Diabetologia 48(1):58-67. doi:10. 1007/s00125-004-1605-2

81. Minamino T, Miyauchi H, Yoshida T, Ishida Y, Yoshida H, Komuro I (2002) Endothelial cell senescence in human atherosclerosis: role of telomere in endothelial dysfunction. Circulation 105(13):1541-1544

82. Harrison DG, Widder J, Grumbach I, Chen W, Weber M, Searles C (2006) Endothelial mechanotransduction, nitric oxide and vascular inflammation. J Intern Med 259(4):351-363. doi:10.1111/j.1365-2796.2006.01621.x

83. Krtolica A, Parrinello S, Lockett S, Desprez PY, Campisi J (2001) Senescent fibroblasts promote epithelial cell growth and tumorigenesis: a link between cancer and aging. Proc Natl Acad Sci USA 98(21):12072-12077

84. Parrinello S, Coppe JP, Krtolica A, Campisi J (2005) Stromalepithelial interactions in aging and cancer: senescent fibroblasts alter epithelial cell differentiation. J Cell Sci 118(Pt 3):485-496. doi: $10.1242 /$ jcs. 01635

85. Bavik C, Coleman I, Dean JP, Knudsen B, Plymate S, Nelson PS (2006) The gene expression program of prostate fibroblast senescence modulates neoplastic epithelial cell proliferation through paracrine mechanisms. Cancer Res 66(2):794-802. doi:10.1158/0008-5472.CAN-05-1716

86. Liu D, Hornsby PJ (2007) Senescent human fibroblasts increase the early growth of xenograft tumors via matrix metalloproteinase secretion. Cancer Res 67(7):3117-3126. doi:10.1158/ 0008-5472.CAN-06-3452

87. Pribluda A, Elyada E, Wiener Z, Hamza H, Goldstein RE, Biton M, Burstain I, Morgenstern Y, Brachya G, Billauer H, Biton S, Snir-Alkalay I, Vucic D, Schlereth K, Mernberger M, Stiewe T, Oren M, Alitalo K, Pikarsky E, Ben-Neriah Y (2013) A senescence-inflammatory switch from cancer-inhibitory to cancerpromoting mechanism. Cancer Cell 24(2):242-256. doi:10. 1016/j.ccr.2013.06.005

88. Kuilman T, Michaloglou C, Vredeveld LC, Douma S, van Doorn R, Desmet CJ, Aarden LA, Mooi WJ, Peeper DS (2008) Oncogene-induced senescence relayed by an interleukindependent inflammatory network. Cell 133(6):1019-1031

89. Lujambio A, Akkari L, Simon J, Grace D, Tschaharganeh DF, Bolden JE, Zhao Z, Thapar V, Joyce JA, Krizhanovsky V, Lowe 
SW (2013) Non-cell-autonomous tumor suppression by p53. Cell 153(2):449-460. doi:10.1016/j.cell.2013.03.020

90. West MD, Pereira-Smith OM, Smith JR (1989) Replicative senescence of human skin fibroblasts correlates with a loss of regulation and overexpression of collagenase activity. Exp Cell Res 184(1):138-147

91. Millis AJ, Hoyle M, McCue HM, Martini H (1992) Differential expression of metalloproteinase and tissue inhibitor of metalloproteinase genes in aged human fibroblasts. Exp Cell Res 201(2):373-379

92. Mawal-Dewan M, Lorenzini A, Frisoni L, Zhang H, Cristofalo VJ, Sell C (2002) Regulation of collagenase expression during replicative senescence in human fibroblasts by Akt-forkhead signaling. J Biol Chem 277(10):7857-7864. doi:10.1074/jbc. M104515200

93. Streuli C (1999) Extracellular matrix remodelling and cellular differentiation. Curr Opin Cell Biol 11(5):634-640

94. Watt FM, Huck WT (2013) Role of the extracellular matrix in regulating stem cell fate. Nat Rev Mol Cell Biol 14(8):467-473. doi: $10.1038 / \mathrm{nrm} 3620$

95. Sottile J (2004) Regulation of angiogenesis by extracellular matrix. Biochim Biophys Acta 1654(1):13-22. doi:10.1016/j. bbcan.2003.07.002

96. Clarke B (2008) Normal bone anatomy and physiology. Clin J Am Soc Nephrol 3(Suppl 3):S131-S139. doi:10.2215/CJN. 04151206

97. Schultz G, Mozingo D, Romanelli M, Claxton K (2005) Wound healing and TIME; new concepts and scientific applications. Wound Repair Regen 13 (4 Suppl):S1-S11. doi:10.1111/j.10671927.2005.1304S1.x

98. Choi HR, Cho KA, Kang HT, Lee JB, Kaeberlein M, Suh Y, Chung IK, Park SC (2011) Restoration of senescent human diploid fibroblasts by modulation of the extracellular matrix. Aging Cell 10(1):148-157. doi:10.1111/j.1474-9726.2010.00654.x

99. Nakano-Kurimoto R, Ikeda K, Uraoka M, Nakagawa Y, Yutaka K, Koide M, Takahashi T, Matoba S, Yamada H, Okigaki M, Matsubara H (2009) Replicative senescence of vascular smooth muscle cells enhances the calcification through initiating the osteoblastic transition. Am J Physiol Heart Circ Physiol 297(5):H1673-H1684. doi:10.1152/ajpheart.00455.2009

100. Burton DG, Matsubara H, Ikeda K (2010) Pathophysiology of vascular calcification: pivotal role of cellular senescence in vascular smooth muscle cells. Exp Gerontol 45(11):819-824. doi:10.1016/j.exger.2010.07.005

101. Liu Y, Drozdov I, Shroff R, Beltran LE, Shanahan CM (2013) Prelamin A accelerates vascular calcification via activation of the DNA damage response and senescence-associated secretory phenotype in vascular smooth muscle cells. Circ Res 112(10):e99-109. doi:10.1161/CIRCRESAHA.111.300543

102. Paradis V, Youssef N, Dargere D, Ba N, Bonvoust F, Deschatrette J, Bedossa P (2001) Replicative senescence in normal liver, chronic hepatitis $\mathrm{C}$, and hepatocellular carcinomas. Hum Pathol 32(3):327-332

103. Wiemann SU, Satyanarayana A, Tsahuridu M, Tillmann HL, Zender L, Klempnauer J, Flemming P, Franco S, Blasco MA, Manns MP, Rudolph KL (2002) Hepatocyte telomere shortening and senescence are general markers of human liver cirrhosis. FASEB J 16(9):935-942

104. Rudolph KL, Chang S, Millard M, Schreiber-Agus N, DePinho RA (2000) Inhibition of experimental liver cirrhosis in mice by telomerase gene delivery. Science 287(5456):1253-1258

105. Herbig U, Ferreira M, Condel L, Carey D, Sedivy JM (2006) Cellular senescence in aging primates. Science 311(5765):1257. doi:10.1126/science.1122446

106. Melk A, Kittikowit W, Sandhu I, Halloran KM, Grimm P, Schmidt BM, Halloran PF (2003) Cell senescence in rat kidneys in vivo increases with growth and age despite lack of telomere shortening. Kidney Int 63(6):2134-2143. doi:10.1046/j.15231755.2003.00032.x

107. Wang C, Jurk D, Maddick M, Nelson G, Martin-Ruiz C, von Zglinicki T (2009) DNA damage response and cellular senescence in tissues of aging mice. Aging Cell 8(3):311-323. doi:10. 1111/j.1474-9726.2009.00481.x

108. Bhat R, Crowe EP, Bitto A, Moh M, Katsetos CD, Garcia FU, Johnson FB, Trojanowski JQ, Sell C, Torres C (2012) Astrocyte senescence as a component of Alzheimer's disease. PLoS One 7(9):e45069. doi:10.1371/journal.pone.0045069

109. Bitto A, Sell C, Crowe E, Lorenzini A, Malaguti M, Hrelia S, Torres C (2010) Stress-induced senescence in human and rodent astrocytes. Exp Cell Res 316(17):2961-2968. doi:10.1016/j. yexcr.2010.06.021

110. Xue W, Zender L, Miething C, Dickins RA, Hernando E, Krizhanovsky V, Cordon-Cardo C, Lowe SW (2007) Senescence and tumour clearance is triggered by p53 restoration in murine liver carcinomas. Nature 445(7128):656-660

111. Soriani A, Zingoni A, Cerboni C, Iannitto ML, Ricciardi MR, Di Gialleonardo V, Cippitelli M, Fionda C, Petrucci MT, Guarini A, Foa R, Santoni A (2009) ATM-ATR-dependent up-regulation of DNAM-1 and NKG2D ligands on multiple myeloma cells by therapeutic agents results in enhanced NK-cell susceptibility and is associated with a senescent phenotype. Blood 113(15):3503-3511

112. Iannello A, Thompson TW, Ardolino M, Lowe SW, Raulet DH (2013) p53-dependent chemokine production by senescent tumor cells supports NKG2D-dependent tumor elimination by natural killer cells. J Exp Med 210(10):2057-2069. doi:10.1084/ jem.20130783

113. Gasser S, Orsulic S, Brown EJ, Raulet DH (2005) The DNA damage pathway regulates innate immune system ligands of the NKG2D receptor. Nature 436(7054):1186-1190

114. Hazeldine J, Lord JM (2013) The impact of ageing on natural killer cell function and potential consequences for health in older adults. Ageing Res Rev 12(4):1069-1078. doi:10.1016/j. arr.2013.04.003

115. Sagiv A, Krizhanovsky V (2013) Immunosurveillance of senescent cells: the bright side of the senescence program. Biogerontology 14(6):617-628. doi:10.1007/s10522-013-9473-0

116. Effros RB, Pawelec G (1997) Replicative senescence of T cells: does the Hayflick limit lead to immune exhaustion? Immunol Today 18(9):450-454

117. Rajagopalan S, Long EO (2012) Cellular senescence induced by CD158d reprograms natural killer cells to promote vascular remodeling. Proc Natl Acad Sci USA 109(50):20596-20601. doi:10.1073/pnas.1208248109

118. Kang TW, Yevsa T, Woller N, Hoenicke L, Wuestefeld T, Dauch D, Hohmeyer A, Gereke M, Rudalska R, Potapova A, Iken M, Vucur M, Weiss S, Heikenwalder M, Khan S, Gil J, Bruder D, Manns M, Schirmacher P, Tacke F, Ott M, Luedde T, Longerich T, Kubicka S, Zender L (2011) Senescence surveillance of pre-malignant hepatocytes limits liver cancer development. Nature 479(7374):547-551. doi:10.1038/ nature 10599

119. Kim YM, Byun HO, Jee BA, Cho H, Seo YH, Kim YS, Park MH, Chung HY, Woo HG, Yoon G (2013) Implications of timeseries gene expression profiles of replicative senescence. Aging Cell 12(4):622-634. doi:10.1111/acel.12087

120. Wang B, Niu D, Lai L, Ren EC (2013) p53 increases MHC class I expression by upregulating the endoplasmic reticulum aminopeptidase ERAP1. Nature Commun 4:2359. doi:10.1038/ ncomms3359

121. Reuschenbach M, von Doeberitz Knebel M, Wentzensen N (2009) A systematic review of humoral immune responses 
against tumor antigens. Cancer Immunol Immunother 58(10):1535-1544. doi:10.1007/s00262-009-0733-4

122. Sanders YY, Liu H, Zhang X, Hecker L, Bernard K, Desai L, Liu G, Thannickal VJ (2013) Histone modifications in senescence-associated resistance to apoptosis by oxidative stress. Redox Biol 1(1):8-16. doi:10.1016/j.redox.2012.11.004

123. Seluanov A, Gorbunova V, Falcovitz A, Sigal A, Milyavsky M, Zurer I, Shohat G, Goldfinger N, Rotter V (2001) Change of the death pathway in senescent human fibroblasts in response to DNA damage is caused by an inability to stabilize p53. Mol Cell Biol 21(5):1552-1564

124. Barzilai A, Biton S, Shiloh Y (2008) The role of the DNA damage response in neuronal development, organization and maintenance. DNA Repair 7(7):1010-1027. doi:10.1016/j. dnarep.2008.03.005
125. Gordon LB, Rothman FG, Lopez-Otin C, Misteli T (2014) Progeria: a paradigm for translational medicine. Cell 156(3):400-407. doi:10.1016/j.cell.2013.12.028

126. Cox LS, Faragher RG (2007) From old organisms to new molecules: integrative biology and therapeutic targets in accelerated human ageing. Cell Mol Life Sci 64(19-20):2620-2641. doi:10. 1007/s00018-007-7123-x

127. Baker DJ, Wijshake T, Tchkonia T, LeBrasseur NK, Childs BG, van de Sluis B, Kirkland JL, van Deursen JM (2011) Clearance of p16Ink4a-positive senescent cells delays ageing-associated disorders. Nature 479(7372):232-236. doi:10.1038/nature10600 